\title{
The Relationship of Patient, Medical and Laboratory Characteristics to Changes in Functional Health Status in Children and Adolescents After the Fontan Procedure
}

\author{
Brian W. McCrindle, MD MPH ${ }^{1}$, Victor Zak, $\mathrm{PhD}^{2}$, Roger E. Breitbart, MD ${ }^{3}$, Lynn Mahony, \\ MD $^{4}$, Peter Shrader, MA ${ }^{2}$, Wyman W. Lai, MD MPH ${ }^{5}$, Kristin M. Burns, MD ${ }^{6}$, Steven D. \\ Colan, MD $^{3}$, Richard V. Williams, MD ${ }^{7}$, David Goldberg, MD ${ }^{8}$, Kevin D. Hill, MD MSCI${ }^{9}$, \\ Svetlana Khaikin, RN MPH ${ }^{1}$, Andrew M. Atz, MD ${ }^{10}$, and for the Pediatric Heart Network \\ Investigators ${ }^{*}$ \\ ${ }^{1}$ University of Toronto, The Hospital for Sick Children, Toronto, Canada \\ ${ }^{2}$ New England Research Institutes, Watertown, MA \\ ${ }^{3}$ Boston Children's Hospital, Boston, MA \\ ${ }^{4}$ University of Texas Southwestern Medical Center, Dallas, TX \\ ${ }^{5}$ Columbia University Medical Center, New York, NY \\ ${ }^{6}$ National Heart, Lung, and Blood Institute, NIH, Besthesda, MD \\ 7 University of Utah, Salt Lake City, UT \\ ${ }^{8}$ Children's Hospital of Philadelphia, Philadelphia, PA \\ ${ }^{9}$ Duke University Medical Center, Durham, NC \\ ${ }^{10}$ Medical University of South Carolina, Charleston, SC
}

\section{Abstract}

\begin{abstract}
Despite hypothesized concerns about deterioration beginning in adolescence, longitudinal data and associated factors regarding standardized assessment of physical functioning are not available for Fontan patients. Parents who participated in the Fontan Cross-Sectional Study completed the Child Health Questionnaire at two time points for 245 subjects ages 6 to 18 years. Associations between change in Physical Functioning Summary Score and baseline patient, medical and laboratory characteristics (mean age 9.5 \pm 1.7 years) and follow-up patient and medical characteristics (mean age $16.2 \pm 1.6$ years) were determined by regression analyses. Over a mean of $6.7 \pm 0.4$ years, a small (not clinically important) but statistically significant decline in score from $46.2 \pm 11.7$ to $44.5 \pm 12.1(\mathrm{p}<0.03)$ was noted. Subjects with higher baseline scores had a greater decline in score $(\mathrm{r}=-0.48 ; \mathrm{p}<0.001)$. A multivariable model of patient and medical characteristics $\left(\mathrm{R}^{2}=0.11\right)$ showed that a greater decline in score was significantly associated with interim development of asthma $(n=13$; parameter estimate $[\mathrm{PE}]-6.6 ; \mathrm{p}<0.05)$ or other chronic respiratory, lung or breathing problems $(n=13 ; \mathrm{PE}-12.5 ; \mathrm{p}<0.001)$, and the presence of protein-losing enteropathy at any time $(\mathrm{n}=12 ; \mathrm{PE}-9.4 ; \mathrm{p}=0.006)$. Change in score was not significantly associated with baseline laboratory measures of exercise capacity and ventricular characteristics and function. Therefore, although physical functioning may be stable during adolescence for many Fontan patients,
\end{abstract}

\footnotetext{
Address for correspondence/reprints: Dr. Brian McCrindle, The Hospital for Sick Children, 555 University Avenue, Toronto, Ontario, Canada M5G 1X8, Ph 416-813-7654 ext 207609; FAX 416-813-7547, brian.mccrindle@ sickkids.ca.

Full list of investigators in online-line Data Supplement

See Online Data Supplement for complete list of investigators.
} 
deterioration occurs in some in association with respiratory conditions and protein-losing enteropathy. Further longitudinal study is necessary to better understand the relationship between clinical morbidities and functional health status as these patients transition into adulthood.

\section{Keywords}

Fontan procedure; heart defects; congenital; pediatrics; functional health status

\section{INTRODUCTION}

Patients with functional single ventricle who have had the Fontan procedure are at risk for important morbidities and functional deterioration.[1-3] Cross-sectional studies performed in this population at various ages have shown some decrements in physical functioning relative to the normal population, and have identified various associated patient and medical characteristics.[4,5] Nonetheless, the proportion of the variation in functional health status explained by these factors has been low, and a paucity of longitudinal data is available.[6,7] Issues regarding accurate conceptualization and assessment of quality of life and functional health status in congenital heart disease populations may limit interpretation of available studies.[8] There are concerns that functional deterioration may be accelerated in adolescence and early adulthood, an observation largely based on clinic populations for which the denominator is not well-characterized, rigorous assessment of physical functioning was not performed, or longitudinal data were lacking.[9]

The Pediatric Heart Network Fontan Cross-Sectional Study (Fontan 1) characterized a multiinstitutional cohort of survivors after the Fontan procedure, with an age at enrollment of 6 to 18 years.[10,11] Cross-sectional assessment included completion of functional health status questionnaires. We have performed a second cross-sectional assessment of this cohort that was limited to collection of clinical events and measurement of functional health status (Fontan 2). The primary objectives of this analysis were to characterize changes in parentreported physical functioning through adolescence, and to identify associated patient and medical factors.

\section{METHODS}

\section{Study Design and Subjects}

The methods for Fontan 1 have been previously described.[10] The current study is an additional cross-sectional assessment of eligible participants from Fontan 1 and was approved by the institutional review board at each center. Medical records and death registries were screened first to identify patients who were alive and had not had cardiac transplantation or conversion to a biventricular circulation. Eligible patients were then approached for participation in the current cross-sectional assessment (Fontan 2), and written informed consent and assent, as appropriate, were obtained for each subject. Enrollment occurred from November 2009 to May 2011.

\section{Enrollment and Data Collection}

Data were abstracted into standardized forms from medical record review, and included updated anatomic, clinical and procedural details since Fontan 1. In addition, current clinical state (height, weight, New York Heart Association heart failure class) and socioeconomic status (Hollingshead Index of Social Status; linkage to United States census data by patient address) were obtained from structured interviews conducted by telephone or in person with the parent/guardian or patient (depending on the age of the patient). 


\section{Health-Related Quality of Life Questionnaire}

At Fontan 1, when participants were 6 to 18 years of age, the parent/guardian completed the Child Health Questionnaire (CHQ) Parent Form (PF50). This questionnaire is normed and validated for children ages 5 to 18 years, as reported in previous publications from Fontan 1. $[6,7,12]$ At Fontan 2, some of the cohort were now 19 years of age and older, and the parent report form of the CHQ no longer applied. Since it was essential to compare scores from identical questionnaires, the study population for the current analysis was restricted to those $<19$ years of age at Fontan 2 and whose parents completed the CHQ PF50 at both time points, either by mail or inperson at the time of a routinely scheduled clinic visit.[13]

The CHQ PF50 produces scores for 14 domains and two summary scores (Physical Functioning; Psychosocial Functioning) calculated from responses. The CHQ also contains a checklist of medical conditions. Data from a normative population of 379 children in the United States are available for comparison.[13] Higher scores indicate better functioning, and from the normative sample, a 5 to 10 point difference in Summary Score represents a clinically meaningful difference.

\section{Data Analysis}

Participants whose parent/guardian completed the CHQ at both Fontan 1 and 2, and had sufficiently completed the questionnaires to allow for calculation of the Physical Functioning Summary Score at both time points, were included in the analysis. To determine potential bias in the studied population, the characteristics of eligible subjects who participated in Fontan 2 were compared to those who participated in Fontan 1 but not Fontan 2 (analysis of variance, Fisher's exact test, Wilcoxon rank sum or Kruskall-Wallis test for unadjusted comparisons; Mantel-Haenszel test for linear trend, regression models for ageadjusted comparisons). The change in the Physical Functioning Summary Score was assessed using a paired $t$ test. Associations between patient, medical, and laboratory testing characteristics and the change in score were determined using linear regression. Bivariable associations and testing for linearity using generalized additive models were first performed for each characteristic. Appropriate variable transformations were explored and applied if non-linearity was significant. Separate stepwise multiple regression analyses were performed for subgroups of characteristics, including interim clinical events and changes in medical conditions between Fontan 1 and 2. Mean imputation (replacement of missing values with the mean of all non-missing values) was used to impute missing values for characteristics before performing multiple regression for analysis of echocardiographic variables only; less than $2 \%$ of values were missing for any given echocardiographic variable. Variable entry and stay significance levels were specified at $\mathrm{p}=0.15$ and $\mathrm{p}=0.05$, respectively. Bootstrap resampling was used to determine variable reliability for model selection. The proportion of variance explained by the model was assessed using $\mathrm{R}^{2}$ and $\mathrm{R}^{2}$ adjusted, which was adjusted downward to account for the effect of increasing $\mathrm{R}^{2}$ due to high variable counts. A final multivariable model was determined for patient and medical characteristics, but not for laboratory testing variables from Fontan 1, as not all subjects underwent all of the tests or had all of the prespecified data.[7] All analyses were performed using SAS statistical software version 9.2 (SAS Institute, Inc., Cary, NC).

\section{RESULTS}

\section{Participation}

Of the 546 subjects who participated in Fontan 1, 30 subjects were not eligible for Fontan 2 ( 1 conversion to biventricular repair, 16 deaths, 11 heart transplantations and 2 who were transplanted and died). Of 516 eligible subjects for Fontan 2, 315 were less than 19 years of age, of whom 42 declined participation or were lost to follow-up. Of those 273 subjects who 
consented for Fontan 2, 28 had no or insufficient data to derive the Physical Functioning Summary Score from the CHQ-PF50 from at least one of the two time points (14 for Fontan 1 only, 12 for Fontan 2 only, 2 for both). Thus, paired data from Fontan 1 and 2 for the Summary Score were available for 245 subjects who comprise the study sample for the current analysis. Figure 1 gives the number of these subjects who had each element of the laboratory testing from Fontan 1.

\section{Participation Bias}

The patient characteristics and laboratory testing results from Fontan 1 for these 245 Fontan 2 participants were compared to the 70 subjects $<19$ years of age who were eligible but declined to participate in Fontan 2 or were lost to follow-up (n=42) or who consented for Fontan 2 participation but did not have CHQ summary scores for both Fontan 1 and 2 $(n=28)$. (Supplementary Table S1). Participants were significantly more likely to be of white race and less likely to identify as "other" (neither black nor white) race. Participants had higher household income, higher level of maternal education, and higher Psychosocial Functioning Summary Scores from Fontan 1, but similar Physical Functioning Summary Scores. No significant differences between participants and non-participants were identified in any cardiac characteristics or laboratory measures from Fontan 1.

\section{Patient Characteristics}

The mean age at enrollment was 9.5 \pm 1.7 years for Fontan 1, and 16.2 \pm 1.6 years at Fontan 2; $59 \%$ were male. Ventricular morphology was left for $47 \%$, right $37 \%$ and mixed for $16 \%$. A staging superior cavopulmonary anastomosis had been performed for $90 \%$. The mean age at Fontan procedure was $2.9 \pm 1.2$ years, with $76 \%$ having an atrial level fenestration. The type of Fontan connection was atriopulmonary for 4\%, intracardiac lateral tunnel for 59\%, extracardiac conduit for $35 \%$ and other connection type for $2 \%$.

\section{Change in Physical Functioning Summary Score}

The mean score at Fontan 1 was $46.2 \pm 11.7$, and at Fontan 2 was $44.5 \pm 12.1$, for a mean change of $-1.7 \pm 11.9\left(25^{\text {th }}\right.$ percentile $-6.9 ; 75^{\text {th }}$ percentile $\left.+4.5 ; \mathrm{p}<0.03\right)$. The mean time interval between Fontan 1 and 2 was $6.7 \pm 0.4$ years. A slope of yearly change in score showed a mean decline of $-0.3 \pm 1.8$ per year. Scores at Fontan 1 and 2 showed a positive linear correlation $(r=0.50 ; p<0.001)$. There was no significant association between the change in score and the time interval between Fontan 1 and 2. Overall, a higher score at Fontan 1 was negatively associated with change in score (parameter estimate [PE] -0.49 ; $\mathrm{p}<0.001$ ), with those with higher scores at Fontan 1 showing a greater decline, while those with lower scores at Fontan 1 showing a greater increase in score at Fontan 2. This likely represents some regression to the mean. The parent or guardian who completed the CHQ at Fontan 2 (88\% female) was the same person as for Fontan 1 (84\% females) for 206 (84\%) participants, with no association with change in score.

\section{Association of Change in Score with Patient Characteristics from Fontan 1}

In bivariable analyses, worsening of Physical Functioning Summary Score was significantly associated with higher score at Fontan $1(\mathrm{PE}-0.5 ; \mathrm{p}<0.001)$, and both white race and black race $(\mathrm{PE}-3.8,-8.8$, respectively; $\mathrm{p}=0.02)$ relative to "other" race. Change in score was not significantly associated with gender, ventricular morphology, staging with a superior cavopulmonary connection, fenestration, type of Fontan connection, age at Fontan 1 or $\mathrm{z}$ score of body mass index at Fontan 1. Only score at Fontan 1 was significant in multivariable modeling (Table 1). 


\section{Association of Change in Score with Socioeconomic Characteristics at Fontan 2}

Worsening score was significantly associated with maternal education beyond some high school (without a gradient with higher category), but not with household income. However, neither socioeconomic status variable had sufficient bootstrap reliability in multivariable modeling.

\section{Association of Change in Score with Baseline Medical History Events Prior to Fontan 1}

In bivariable analyses, subsequent worsening of score was significantly associated with the presence of protein-losing enteropathy ( $\mathrm{PE}-19.8$; $\mathrm{p}<0.001$; however, it was present in only 5 current participants at Fontan 1). Worsening of score was not associated with the presence of stroke, seizure ( $\mathrm{p}=0.06$ ), thrombosis or arrhythmia. The presence of other important complications (heterogenous and low frequency complications) at or prior to Fontan 1 was also associated with worsening of score $(\mathrm{PE}-4.0 ; \mathrm{p}=0.03)$. There was no significant association between change in score and cardiac surgical or catheter intervention procedures at or prior to Fontan 1. Multivariable modeling showed protein-losing enteropathy at or prior to Fontan 1 to be significantly associated with worsening of score (Table 1).

\section{Association of Change in Score with Non-Cardiac Medical Conditions Reported at Fontan 1}

For parent-reported medical conditions at Fontan 1, the presence of chronic respiratory, lung or breathing problems other than asthma $(\mathrm{n}=20)$ was significantly associated in both bivariable and multivariable analyses with an improvement in score, although the proportion of variance explained was very small (Table 1). Change in score was not significantly associated with the following medical conditions present at Fontan 1: asthma, chronic allergies or sinus trouble, chronic orthopedic, bone or joint problems, chronic rheumatic disease, diabetes, epilepsy/seizure disorder, hearing impairment or deafness, speech problems, vision problems, developmental delay or mental retardation, anxiety problems, attention problems, learning problems, behavioral problems, depression, sleep disturbance, or other chronic medical condition. The prevalence of these conditions at Fontan 1 has been previously reported.[6]

\section{Association of Change in Score with Interim Medical History Events Between Fontan 1 and 2}

For Fontan 2, data regarding interim medical history events between Fontan 1 and 2 were recorded. An exception was made for cirrhosis, plastic bronchitis and protein-losing enteropathy to include onset prior to Fontan 1 , since these conditions uniformly persisted in the interim and, hence, were combined with new occurences. In bivariable analyses, the interim development of arrhythmia ( 29 subjects; PE $-8.8 ; \mathrm{p}<0.001)$ and the development of protein-losing enteropathy at any timepoint ( 13 subjects; $\mathrm{PE}-10.3 ; \mathrm{p}=0.002)$ were significantly associated with a worsening score. There was no significant association with interim cardiac surgical or catheter intervention procedures (including pacemaker insertion), or other complications (no strokes, 3 subjects with seizure, 5 with thrombosis, 5 with cirrhosis, 1 with plastic bronchitis, 79 with other heterogeneous and low frequency important complications). Both interim development of arrhythmia and the development of protein-losing enteropathy at any timepoint were significant in multivariable modeling (Table 1). When both baseline and interim medical history events were combined, multivariable modeling showed that arrhythmia (overall 50 subjects; $\mathrm{PE}-3.9 ; \mathrm{p}=0.04$; reliability $50 \%$ ) and protein-losing enteropathy (13 subjects; $\mathrm{PE}-10.2 ; \mathrm{p}=0.002$; reliability $82 \%$ ) occurring at any time prior to Fontan 2 remained significantly associated with worsening in score (adjusted $\mathrm{R}^{2}=0.06$ ). 


\section{Association of Change in Score with Interim Change in Non-Cardiac Medical Conditions Between Fontan 1 and 2}

In bivariable analyses, worsening in score was significantly associated with new onset of asthma (13 subjects; PE -8.5; $\mathrm{p}<0.02$ ), new onset of chronic respiratory, lung or breathing problems other than asthma (13 subjects; $\mathrm{PE}-14.8 ; \mathrm{p}<0.001)$, and with new onset of any "other" chronic medical condition (34 subjects; $\mathrm{PE}-5.2 ; \mathrm{p}<0.02$ ). In multivariable modeling, only interim development of chronic respiratory, lung or breathing problems other than asthma remained significant (Table 1). Of note, change in score was not significantly associated with changes in z-score of body mass index from Fontan 1 to 2 ( $\mathrm{n}=240 ;$ PE 0.2; $\mathrm{p}=0.86$ ).

\section{Final Multivariable Model for Patient and Medical Characteristics}

A final multivariable model for worsening score was explored that included all of the preceding variables. This model (Table 1) included interim development of chronic respiratory, lung or breathing problems other than asthma, interim development of asthma, and development of protein-losing enteropathy at any timepoint.

\section{Association of Change in Score with Exercise Testing Variables from Fontan 1}

Exercise testing with an adequate effort (respiratory exchange ratio >1.1) was achieved at Fontan 1 for 40 participants included in the current analysis. In bivariable analyses, worsening in score was significantly associated with a higher percent predicted oxygen consumption at peak exercise ( $\mathrm{PE}-0.32 ; \mathrm{p}=0.02)$ and higher precent predicted oxygen pulse (PE -0.16; $\mathrm{p}<0.05$ ). Neither variable had sufficient bootstrap reliability (reliability $\geq 45 \%$ ) in multivariable modeling.

\section{Association of Change in Score with Echocardiographic Variables from Fontan 1}

Of 16 variables from echocardiography performed at Fontan 1 ( $n=194$ of Fontan 2 participants), only lower tissue Doppler peak early diastolic velocity ( $\mathrm{n}=162 ; \mathrm{PE} 0.66$; $\mathrm{p}<0.05$ ) was significantly associated with worsening in score in bivariable analyses, with no variable having sufficient bootstrap reliability in multivariable modeling. This finding remained unchanged when missing values for echocardiographic variables were imputed with mean imputation.

\section{Association of Change in Score with Magnetic Resonance Imaging Variables from Fontan 1}

Of 7 variables from magnetic resonance imaging performed at Fontan 1 and limited to those assessments for which mass/volume data were able to be calculated ( $\mathrm{n}=70$ of Fontan 2 participants), no variable was significantly associated with worsening of score in bivariable or multivariable analyses.

\section{Association of Change in Score with Brain Natriuretic Peptide Level from Fontan 1}

As the distribution of brain natriuretic peptide (BNP) levels was skewed, a normalizing logarthimic transformation was used in analyses. LogBNP from Fontan $1(n=228$ of Fontan 2 participants) was not significantly associated with change in score $(\mathrm{p}=0.60)$, even after adjusting for age and gender.

\section{Factors Associated with Change in Score Adjusted for Baseline Score at Fontan 1}

Given the observation of greater reduction in Physical Functioning Score with higher baseline score at Fontan 1, a further regression analysis was explored adjusting for baseline score. A multivariable model for decline in score was explored that considered for inclusion 
all previously described patient and parent characteristics, as well as medical events and conditions (laboratory testing variables were not considered as few subjects had all tests). This model $\left(\mathrm{n}=200\right.$, adjusted $\left.\mathrm{R}^{2}=0.47\right)$ included higher baseline score at Fontan $1(\mathrm{PE}-0.71$; $\mathrm{p}<0.001$; reliability 100\%); presence of chronic orthopedic, bone or joint problems at Fontan $1(n=14 ; P E-9.76 ; p<0.001$; reliability $50 \%)$; presence of seizure $(n=7 ; P E-8.77 ; p=0.02$; reliability $51 \%)$ or arrhythmia at any time before Fontan $2(\mathrm{n}=41 ; \mathrm{PE}-7.32 ; \mathrm{p}<0.001$; reliability $89 \%)$; interim development of asthma $(n=12 ; P E-5.77 ; p=0.04$; reliability $63 \%)$ or non-asthma chronic respiratory, lung or breathing problems between Fontan 1 and 2 $(\mathrm{n}=12 ; \mathrm{PE}-10.36 ; \mathrm{p}<0.001$; reliability $75 \%)$, and lower category of household income at Fontan 1 ( $<<0.001$; reliability 75\%). Adjustment for baseline score at Fontan 1 did not change the lack of association between change in score and laboratory measures from Fontan 1. Protein-losing enteropathy was not retained in this model adjusted for baseline score. Nonetheless, the score for these participants decreased from $46.8 \pm 8.2$ at Fontan 1 to $35.3 \pm 15.6$ at Fontan 2 .

\section{DISCUSSION}

\section{Summary}

We noted a small (not clinically important) but statistically significant decline in mean Physical Functioning Summary Score in a cohort of adolescent Fontan subjects over a mean period of $6.7 \pm 0.4$ years. Subjects with a higher baseline score from Fontan 1 had a greater decline in score. A decline in score was independently associated with both cardiac and noncardiac medical conditions, specifically respiratory conditions, seizure, arrhythmia and protein-losing enteropathy. There were no significant associations with baseline laboratory measures of exercise capacity and ventricular characteristics and function in subsets of subjects who had undergone this testing at Fontan 1.

\section{Functional Health Status}

Subjects after Fontan procedure are at risk for important morbidity and physiologic limitations that may impact both physical and psychosocial aspects of functioning. We have previously shown that Fontan subjects not only have lower physical functioning compared to their normal peers, but also lower compared to other populations with cardiac and other chronic diseases.[6] This observation has also been reported in other studies, and with other assessment measures. $[4,14]$ Factors associated with poorer physical functioning in this population are not completely understood. Some associations with objective measures of exercise capacity have been reported.[7,15] Indicators of lower socioeconomic status, presence of non-cardiac medical conditions, current medications and some Fontan characteristics were noted to be associated factors in our previous report of the Fontan 1 study.[6] Exercise capacity and levels of daily physical activity have been shown to deteriorate through adolescence in Fontan subjects.[15-17] There is also felt to be an accelerating risk of cardiac complications, [18-20] as well as Fontan "failure" into adulthood, contributing to mortality and necessitating cardiac transplantation. Given the lack of rigorous, longitudinal assessment of functional health status, the rate of decline and associated factors are poorly understood. This limits the ability to prognosticate and potentially prevent and reverse declining physical functioning.

\section{Respiratory Conditions}

We noted a clinically important deterioration in Physical Functioning Summary Score with the interim development of chronic respiratory, lung or breathing problems other than asthma. In an analysis of Fontan 1 data, non-cardiac conditions, specifically those which were more likely to cause symptoms or limitations on a frequent basis and with greater immediacy, showed greater cross-sectional associations with reduced physical functioning 
scores.[6] Respiratory conditions could be so characterized, and both asthma and nonasthma respiratory problems were noted in the analysis of Fontan 1 to have a cross-sectional association with lower physical functioning summary score, although they did not seem to be more prevalent than in a normative population.[6] In addition, while not previously reported, respiratory conditions may have a greater adverse impact on patients with Fontan physiology. Chronic respiratory inflammation may be associated with increased systemic arterial stiffness, adversely affecting ventricular mechanics and remodeling.[21-23] Increases in airway and intrathoracic pressure may impede venous return and increase pulmonary vascular resistance (most evident with sleep-disordered breathing), elevating Fontan circuit pressures. [24,25] Chronic respiratory conditions may also limit physical activity and predispose to obesity, which is associated with adverse ventricular remodeling. [26] Recent studies have suggested a role for pulmonary vasodilators for improving or preventing decline in exercise capacity and improving ventricular mechanics.[27-29]

\section{Arrhythmia}

The presence and development of arrhythmia was associated with a significant decline in physical functioning score. Very few data are available regarding functional health status in the setting of pediatric arrhythmia, although specific assessment instruments are being developed.[30] Our data are consistent with the findings of the few published studies in this area. Li et al. showed important declines in exercise tolerance for adults with congenital heart disease who developed atrial flutter.[31] Strieper et al. noted an improvement in quality of life scores for children without structural heart disease who had ablation for supraventricular tachycardia.[32] Patients with implanted defibrillators have been shown to have worse physical and psychosocial functioning than patients after Fontan procedure or with other cardiac conditions. [6,33-35] Hiramatsu et al. noted an improvement in New York Heart Association functional class after Fontan conversion with arrhythmia surgery and pacemaker therapy.[36] An analysis of Fontan 1 data showed that patients who had pacemaker placement had lower Physical Functioning Summary Scores, although this was not associated with change in score in the current analysis.[37]

\section{Protein-losing enteropathy}

Although protein-losing enteropathy is a relatively uncommon complication after Fontan procedure, it remains difficult to both predict and to treat.[38] Protein-losing enteropathy is a common indication for cardiac transplantation, noted in approximately $40 \%$ of patients transplanted for failed Fontan.[39,40] Patients with protein-losing enteropathy who have worse functional health status have increased mortality. Silvairat et al. reported a hazard ratio of 4.0 for time-related mortality for those patients with protein-losing enteropathy who were in New York Heart Association class III or IV.[41] The current study highlights a clinically important deterioration in physical functioning both in patients who had proteinlosing enteropathy at baseline or who subsequently developed it during follow-up.

\section{Limitations}

The results of this study must be viewed in light of some limitations, most of which have been described in previous publications from Fontan 1.[6,7] These relate primarily to the representativeness of the cohort, given that the denominator is not defined and selection bias may be present. This may be magnified by drop-outs and exclusions for the current study.

The assessment of functional health status by parent- or proxy-report may be less valid, and we have previously documented differences from self-report.[12] We chose to use parentreport to maintain consistency with the instrument used in Fontan 1, and to take advantage of the fact that the majority of Fontan 2 participants fell within the age range validated for the Parent Report form of the CHQ. Given the paucity of data on longitudinal assessment 
with the CHQ, the responsiveness of the physical functioning summary score to changes in patient and medical characteristics is not known. The time frame of nearly 7 years between Fontan 1 and 2 may have been too short to observe meaningful changes in functional health status and medical conditions, and may have influenced the detection of associations. Likewise, the age range at both time points may have placed the observation during a time period of stability, and greater changes may be observed over the transition into adulthood. Some of the changes in scores may have represented regression to the mean. However, adjustment in the association analyses for baseline score at Fontan 1 did not produce meaningful changes in findings. Meaningful associations may lie in the changes in laboratory testing measures over time, which were not assessed at Fontan 2, but will be the subject of future study.

\section{Conclusions and Implications}

We conclude that while adolescence may be a period of stability for many Fontan patients in terms of physical functioning, important deterioration occurs in some patients in association with the development of respiratory conditions and protein-losing enteropathy. Baseline laboratory measures appear to be poorly predictive of deterioration. Ongoing rigorous and longitudinal study of functional health status into adulthood is necessary to allow for a better understanding of the relationship between clinical morbidities and functional health status in this at risk group of patients with complex congenital heart disease.

\section{Supplementary Material}

Refer to Web version on PubMed Central for supplementary material.

\section{Acknowledgments}

\section{FUNDING SOURCES}

Supported by U01 grants from the National Heart, Lung, and Blood Institute (HL068269, HL068270, HL068279, HL068281, HL068285, HL068292, HL068290, HL068288). Its contents are solely the responsibility of the authors and do not necessarily represent the official views of NHLBI or NIH.

\section{REFERENCES}

1. Freedom RM, Hamilton R, Yoo SJ, Mikailian H, Benson L, McCrindle B, Justino H, Williams WG. The Fontan procedure: analysis of cohorts and late complications. Cardiol Young. 2000; 10:307331. [PubMed: 10950328]

2. Gersony WM. Fontan operation after 3 decades: what we have learned. Circulation. 2008; 117:1315. [PubMed: 18172049]

3. Pike NA, Evangelista LS, Doering LV, Koniak-Griffin D, Lewis AB, Child JS. Clinical profile of the adolescent/adult Fontan survivor. Congenit Heart Dis. 2011; 6:9-17. [PubMed: 21269408]

4. Manlhiot C, Knezevich S, Radojewski E, Cullen-Dean G, Williams WG, McCrindle BW. Functional health status of adolescents after the Fontan procedure -- comparison with their siblings. Can J Cardiol. 2009; 25:e294-e300. [PubMed: 19746247]

5. Pike NA, Evangelista LS, Doering LV, Eastwood JA, Lewis AB, Child JS. Quality of life, health status, and depression: comparison between adolescents and adults after the Fontan procedure with healthy counterparts. J Cardiovasc Nurs. 2012; 27:539-546. [PubMed: 21912272]

6. McCrindle BW, Williams RV, Mitchell PD, Hsu DT, Paridon SM, Atz AM, Li JS, Newburger JW. Relationship of patient and medical characteristics to health status in children and adolescents after the Fontan procedure. Circulation. 2006; 113:1123-1129. [PubMed: 16490823]

7. McCrindle BW, Zak V, Sleeper LA, Paridon SM, Colan SD, Geva T, Mahony L, Li JS, Breitbart RE, Margossian R, Williams RV, Gersony WM, Atz AM. Laboratory measures of exercise capacity 
and ventricular characteristics and function are weakly associated with functional health status after Fontan procedure. Circulation. 2010; 121:34-42. [PubMed: 20026781]

8. Moons P, Van Deyk K, Budts W, De Geest S. Caliber of quality-of-life assessments in congenital heart disease: a plea for more conceptual and methodological rigor. Archives of pediatrics \& adolescent medicine. 2004; 158:1062-1069. [PubMed: 15520344]

9. van den Bosch AE, Roos-Hesselink JW, Van Domburg R, Bogers AJ, Simoons ML, Meijboom FJ. Long-term outcome and quality of life in adult patients after the Fontan operation. Am J Cardiol. 2004; 93:1141-1145. [PubMed: 15110207]

10. Sleeper LA, Anderson P, Hsu DT, Mahony L, McCrindle BW, Roth SJ, Saul JP, Williams RV, Geva T, Colan SD, Clark BJ. Design of a large cross-sectional study to facilitate future clinical trials in children with the Fontan palliation. Am Heart J. 2006; 152:427-433. [PubMed: 16923408]

11. Anderson PA, Sleeper LA, Mahony L, Colan SD, Atz AM, Breitbart RE, Gersony WM, Gallagher D, Geva T, Margossian R, McCrindle BW, Paridon S, Schwartz M, Stylianou M, Williams RV, Clark BJ 3rd. Contemporary outcomes after the Fontan procedure: a Pediatric Heart Network multicenter study. J Am Coll Cardiol. 2008; 52:85-98. [PubMed: 18598886]

12. Lambert LM, Minich LL, Newburger JW, Lu M, Pemberton VL, McGrath EA, Atz AM, Xu M, Radojewski E, Servedio D, McCrindle BW. Parent- versus child-reported functional health status after the Fontan procedure. Pediatrics. 2009; 124:e942-e949. [PubMed: 19841109]

13. Landgraf, JM.; Abetz, L.; Ware, JEJ. Child Health Questionnaire. Boston, MA: The Health Institute, New England Medical Centrer; 1996.

14. Marino BS, Shera D, Wernovsky G, Tomlinson RS, Aguirre A, Gallagher M, Lee A, Cho CJ, Stern W, Davis L, Tong E, Teitel D, Mussatto K, Ghanayem N, Gleason M, Gaynor JW, Wray J, Helfaer MA, Shea JA. The development of the pediatric cardiac quality of life inventory: a quality of life measure for children and adolescents with heart disease. Qual Life Res. 2008; 17:613-626. [PubMed: 18347927]

15. McCrindle BW, Williams RV, Mital S, Clark BJ, Russell JL, Klein G, Eisenmann JC. Physical activity levels in children and adolescents are reduced after the Fontan procedure, independent of exercise capacity, and are associated with lower perceived general health. Arch Dis Child. 2007; 92:509-514. [PubMed: 17307794]

16. Paridon SM, Mitchell PD, Colan SD, Williams RV, Blaufox A, Li JS, Margossian R, Mital S, Russell J, Rhodes J. A cross-sectional study of exercise performance during the first 2 decades of life after the Fontan operation. J Am Coll Cardiol. 2008; 52:99-107. [PubMed: 18598887]

17. Jenkins PC, Chinnock RE, Jenkins KJ, Mahle WT, Mulla N, Sharkey AM, Flanagan MF. Decreased exercise performance with age in children with hypoplastic left heart syndrome. J Pediatr. 2008; 152:507-512. [PubMed: 18346505]

18. Diller GP, Giardini A, Dimopoulos K, Gargiulo G, Muller J, Derrick G, Giannakoulas G, Khambadkone S, Lammers AE, Picchio FM, Gatzoulis MA, Hager A. Predictors of morbidity and mortality in contemporary Fontan patients: results from a multicenter study including cardiopulmonary exercise testing in 321 patients. Eur Heart J. 2010; 31:3073-3083. [PubMed: 20929979]

19. Khairy P, Fernandes SM, Mayer JE Jr, Triedman JK, Walsh EP, Lock JE, Landzberg MJ. Longterm survival, modes of death, and predictors of mortality in patients with Fontan surgery. Circulation. 2008; 117:85-92. [PubMed: 18071068]

20. Ghanayem NS, Berger S, Tweddell JS. Medical management of the failing Fontan. Pediatr Cardiol. 2007; 28:465-471. [PubMed: 17763892]

21. Weiler Z, Zeldin Y, Magen E, Zamir D, Kidon MI. Pulmonary function correlates with arterial stiffness in asthmatic patients. Respir Med. 2010; 104:197-203. [PubMed: 19892539]

22. Ayer JG, Belousova EG, Harmer JA, Toelle B, Celermajer DS, Marks GB. Lung function is associated with arterial stiffness in children. PLoS One. 2011; 6:e26303. [PubMed: 22046271]

23. Albu A, Fodor D, Bondor C, Suciu O. Carotid arterial stiffness in patients with chronic obstructive pulmonary disease. Acta Physiol Hung. 2011; 98:117-127. [PubMed: 21616770]

24. Shafer KM, Garcia JA, Babb TG, Fixler DE, Ayers CR, Levine BD. The importance of the muscle and ventilatory blood pumps during exercise in patients without a subpulmonary ventricle (Fontan operation). J Am Coll Cardiol. 2012; 60:2115-2121. [PubMed: 23083785] 
25. Watson NF, Bushnell T, Jones TK, Stout K. A novel method for the evaluation and treatment of obstructive sleep apnea in four adults with complex congenital heart disease and Fontan repairs. Sleep Breath. 2009; 13:421-424. [PubMed: 19449048]

26. Cohen MS, Zak V, Atz AM, Printz BF, Pinto N, Lambert L, Pemberton V, Li JS, Margossian R, Dunbar-Masterson C, McCrindle BW. Anthropometric measures after Fontan procedure: implications for suboptimal functional outcome. Am Heart J. 2010; 160:1092-1098. 1098 e1091. [PubMed: 21146663]

27. Goldberg DJ, French B, McBride MG, Marino BS, Mirarchi N, Hanna BD, Wernovsky G, Paridon SM, Rychik J. Impact of oral sildenafil on exercise performance in children and young adults after the fontan operation: a randomized, double-blind, placebo-controlled, crossover trial. Circulation. 2011; 123:1185-1193. [PubMed: 21382896]

28. Goldberg DJ, French B, Szwast AL, McBride MG, Marino BS, Mirarchi N, Hanna BD, Wernovsky G, Paridon SM, Rychik J. Impact of sildenafil on echocardiographic indices of myocardial performance after the Fontan operation. Pediatr Cardiol. 2012; 33:689-696. [PubMed: 22331056]

29. Ovaert C, Thijs D, Dewolf D, Ottenkamp J, Dessy H, Moons P, Gewillig M, Mertens L. The effect of bosentan in patients with a failing Fontan circulation. Cardiol Young. 2009; 19:331-339. [PubMed: 19519964]

30. Pulgaron ER, Wile D, Schneider K, Young ML, Delamater AM. Quality of life and psychosocial functioning of children with cardiac arrhythmias. Cardiol Young. 2012:1-7.

31. Li W, Somerville J, Gibson DG, Henein MY. Effect of atrial flutter on exercise tolerance in patients with grown-up congenital heart (GUCH). Am Heart J. 2002; 144:173-179. [PubMed: 12094205]

32. Strieper M, Leong T, Bajaj T, Huckaby J, Frias P, Campbell R. Does ablation of supraventricular tachycardia in children with a structurally normal heart improve quality of life? Congenit Heart Dis. 2010; 5:587-593. [PubMed: 21106019]

33. Czosek RJ, Bonney WJ, Cassedy A, Mah DY, Tanel RE, Imundo JR, Singh AK, Cohen MI, Miyake CY, Fawley K, Marino BS. Impact of cardiac devices on the quality of life in pediatric patients. Circ Arrhythm Electrophysiol. 2012; 5:1064-1072. [PubMed: 23212181]

34. DeMaso DR, Lauretti A, Spieth L, van der Feen JR, Jay KS, Gauvreau K, Walsh EP, Berul CI. Psychosocial factors and quality of life in children and adolescents with implantable cardioverterdefibrillators. Am J Cardiol. 2004; 93:582-587. [PubMed: 14996583]

35. Koopman HM, Vrijmoet-Wiersma CM, Langius JN, van den Heuvel F, Clur SA, Blank CA, Blom NA, ten Harkel AD. Psychological functioning and disease-related quality of life in pediatric patients with an implantable cardioverter defibrillator. Pediatr Cardiol. 2012; 33:569-575. [PubMed: 22314365]

36. Hiramatsu T, Iwata Y, Matsumura G, Konuma T, Yamazaki K. Impact of Fontan conversion with arrhythmia surgery and pacemaker therapy. Eur J Cardiothorac Surg. 2011; 40:1007-1010. [PubMed: 21354811]

37. Williams RV, Travison T, Kaltman JR, Cecchin F, Colan SD, Idriss SF, Lu M, Margossian R, Reed JH, Silver ES, Stephenson EA, Vetter VL. Comparison of Fontan survivors with and without pacemakers: a report from the Pediatric Heart Network Fontan Cross-Sectional Study. Congenit Heart Dis. 2013; 8:32-39. [PubMed: 22762157]

38. Sable C, Foster E, Uzark K, Bjornsen K, Canobbio MM, Connolly HM, Graham TP, Gurvitz MZ, Kovacs A, Meadows AK, Reid GJ, Reiss JG, Rosenbaum KN, Sagerman PJ, Saidi A, Schonberg $\mathrm{R}$, Shah S, Tong E, Williams RG. Best practices in managing transition to adulthood for adolescents with congenital heart disease: the transition process and medical and psychosocial issues: a scientific statement from the American Heart Association. Circulation. 2011; 123:14541485. [PubMed: 21357825]

39. Davies RR, Sorabella RA, Yang J, Mosca RS, Chen JM, Quaegebeur JM. Outcomes after transplantation for "failed" Fontan: a single-institution experience. J Thorac Cardiovasc Surg. 2012; 143:1183-1192 e1184. [PubMed: 22500594]

40. Kanter KR, Mahle WT, Vincent RN, Berg AM, Kogon BE, Kirshbom PM. Heart transplantation in children with a Fontan procedure. Ann Thorac Surg. 2011; 91:823-829. discussion 829-830.

[PubMed: 21353006] 
41. Silvilairat S, Cabalka AK, Cetta F, Grogan M, Hagler DJ, O'Leary PW. Protein-losing enteropathy after the Fontan operation: associations and predictors of clinical outcome. Congenit Heart Dis. 2008; 3:262-268. [PubMed: 18715460] 


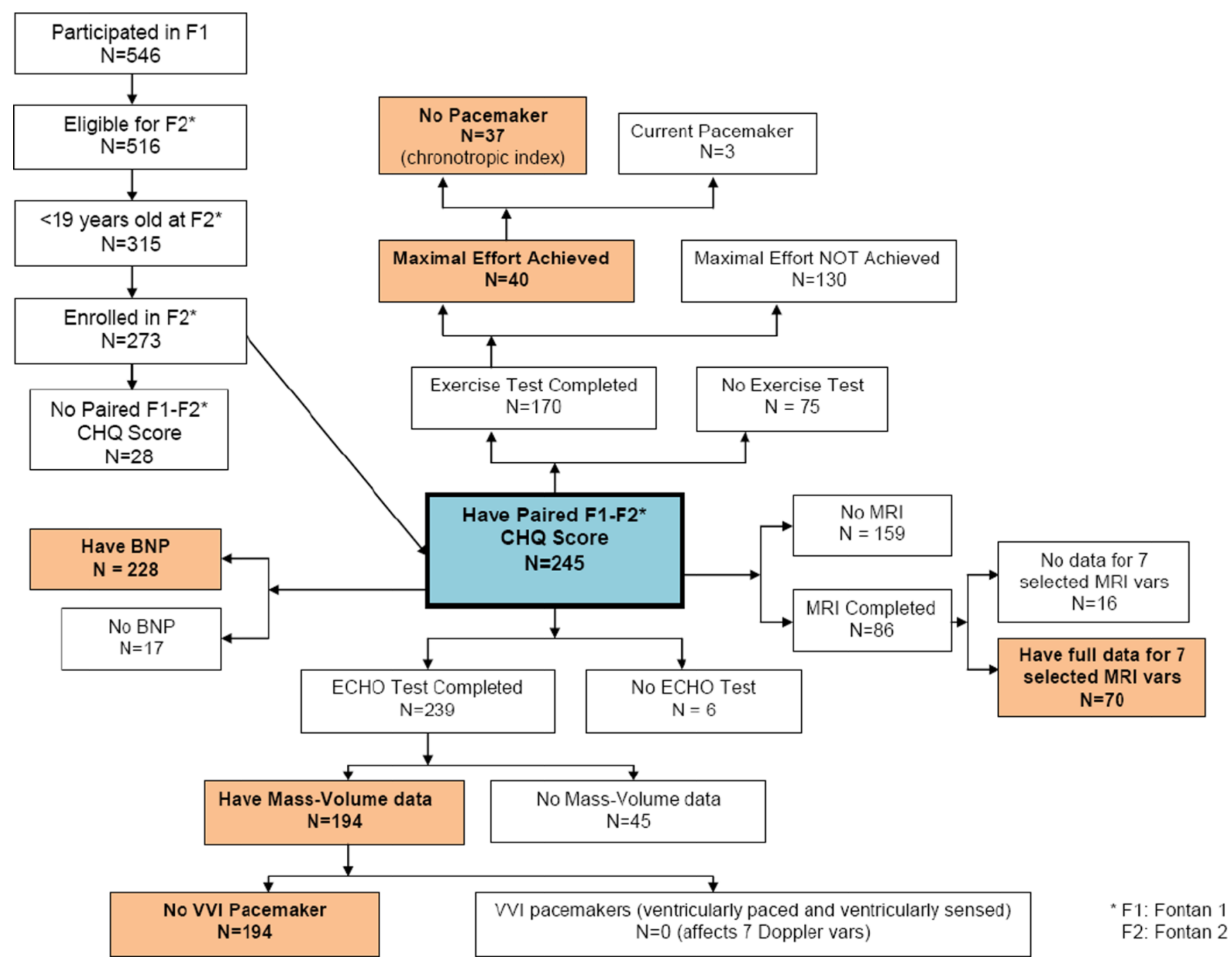

Figure 1.

Level of participation at baseline (Fontan 1) in laboratory testing for 245 participants who had Physical Functioning Summary Scores from the Parent Report Child Health

Questionnaire completed at both Fontan 1 and Fontan 2. Color shading highlights the number of patients with data for each analysis of associations with test type.

BNP, brain natriuretic peptide; CHQ, Child Health Questionnaire; ECHO,

echocardiography; F1, Fontan 1 study; F2, Fontan 2 study; MRI, magnetic resonance imaging; vars, variables 
Table 1

Factors from Multivariable Models of Variable Subsets Associated with Change in Physical Functioning Summary Score.

\begin{tabular}{|c|c|c|c|}
\hline & $\mathbf{P E}$ & p value & Reliability \\
\hline \multicolumn{4}{|l|}{ Patient Characteristics from Fontan $1\left(\mathrm{n}=245 ; \mathrm{R}^{2} 0.23\right)$} \\
\hline Physical Functioning Summary Score at Fontan 1 & -0.49 & $<0.001$ & $100 \%$ \\
\hline \multicolumn{4}{|l|}{$\underline{\text { Socioecomonic Characteristics at Fontan } 2}$} \\
\hline \multicolumn{4}{|l|}{ No variables were sufficiently reliable } \\
\hline \multicolumn{4}{|l|}{ Baseline Medical History Events Before or at Fontan $1\left(n=245 ; \operatorname{adjR} R^{2} 0.06\right)$} \\
\hline Protein-losing enteropathy $(n=5)$ & -20.0 & $<0.001$ & $89 \%$ \\
\hline Seizures $(n=5)$ & -10.7 & $<0.05$ & $47 \%$ \\
\hline \multicolumn{4}{|l|}{$\underline{\text { Non-Cardiac Medical Conditions Before or at Fontan } 1\left(n=241 ; R^{2} 0.02\right)}$} \\
\hline Chronic respiratory, lung or breathing problems other than asthma $(n=20)$ & 6.7 & 0.02 & $65 \%$ \\
\hline \multicolumn{4}{|l|}{ 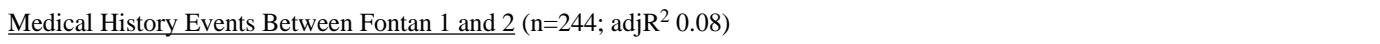 } \\
\hline Arrhythmia $(\mathrm{n}=29)$ & -8.2 & $<0.001$ & $85 \%$ \\
\hline Protein-losing enteropathy at any timepoint $(\mathrm{n}=13)$ & -9.3 & 0.005 & $81 \%$ \\
\hline \multicolumn{4}{|l|}{ Change in Non-Cardiac Conditions Between Fontan 1 and $2\left(n=236 ; R^{2} 0.08\right)$} \\
\hline Development of chronic respiratory, lung or breathing problems other than asthma $(n=13)$ & -14.8 & $<0.001$ & $84 \%$ \\
\hline \multicolumn{4}{|l|}{$\underline{\text { All Patient and Medical Characteristics }}\left(\mathrm{n}=232 ; \operatorname{adj}^{2} 0.11\right)$} \\
\hline Interim development of chronic respiratory, lung or breathing problems other than asthma $(\mathrm{n}=13)$ & -12.5 & $<0.001$ & $82 \%$ \\
\hline Interim development of asthma $(\mathrm{n}=13)$ & -6.6 & $<0.05$ & $45 \%$ \\
\hline Protein-losing enteropathy at an timepoint $(n=12)$ & -9.4 & 0.006 & $55 \%$ \\
\hline \multicolumn{4}{|l|}{ Exercise Testing Variables from Fontan 1} \\
\hline \multicolumn{4}{|l|}{ No variables were sufficiently reliable } \\
\hline \multicolumn{4}{|l|}{ Echocardiographic Variables from Fontan 1} \\
\hline \multicolumn{4}{|l|}{ No variables were sufficiently reliable } \\
\hline \multicolumn{4}{|l|}{ Magnetic Resonance Imaging Variables from Fontan 1} \\
\hline \multicolumn{4}{|l|}{ No variables were sufficiently reliable } \\
\hline \multicolumn{4}{|l|}{ Brain Natriuretic Peptide Level from Fontan 1} \\
\hline No significant association & & & \\
\hline
\end{tabular}

$\operatorname{adj} R^{2}, R^{2}$ adjusted for the number of variables retained in the model; PE, parameter estimate (change in score associated with that variable) 